\title{
Synchronous Condenser Allocation for Improving System Short Circuit Ratio
}

Jia, Jundi; Yang, Guangya; Nielsen, Arne Hejde; Weinreich-Jensen, Peter; Muljadi, Eduard; Gevorgian, Vahan

Published in:

Proceedings of 5th International Conference on Electric Power and Energy Conversion Systems

Link to article, DOI:

10.1109/EPECS.2018.8443358

Publication date:

2018

Document Version

Peer reviewed version

Link back to DTU Orbit

Citation (APA):

Jia, J., Yang, G., Nielsen, A. H., Weinreich-Jensen, P., Muljadi, E., \& Gevorgian, V. (2018). Synchronous Condenser Allocation for Improving System Short Circuit Ratio. In Proceedings of 5 th International Conference on Electric Power and Energy Conversion Systems [Paper 49] IEEE.

https://doi.org/10.1109/EPECS.2018.8443358

\section{General rights}

Copyright and moral rights for the publications made accessible in the public portal are retained by the authors and/or other copyright owners and it is a condition of accessing publications that users recognise and abide by the legal requirements associated with these rights.

- Users may download and print one copy of any publication from the public portal for the purpose of private study or research.

- You may not further distribute the material or use it for any profit-making activity or commercial gain

- You may freely distribute the URL identifying the publication in the public portal 


\section{Synchronous Condenser Allocation for Improving System Short Circuit Ratio}

\author{
Jundi Jia, Guangya Yang and Arne Hejde Nielsen \\ Center for Electric Power and Energy, Technical University of Denmark \\ Kgs. Lyngby 2800, Denmark \\ \{junjia, gyy, ahn\}@elektro.dtu.dk \\ Eduard Muljadi, Fellow, IEEE \\ Department of Electrical and Computer Engineering, Auburn University \\ Auburn, AL 36849, USA \\ mze0018@auburn.edu
}

\author{
Peter Weinreich-Jensen \\ Siemens A/S \\ Ballerup 2750, Denmark \\ peter.Weinreich-Jensen@siemens.com \\ Vahan Gevorgian \\ National Renewable Energy Laboratory \\ Golden, CO 80401, USA \\ vahan.gevorgian@nrel.gov
}

\begin{abstract}
With converter-based renewable energy sources increasingly integrated into power systems and conventional power plants gradually phased out, future power systems will experience reduced short circuit strength. The deployment of synchronous condensers can serve as a potential solution. This paper presents an optimal synchronous condenser allocation method for improving system short circuit ratio at converter point of common coupling using a modified short circuit analysis approach. The total cost of installing new synchronous condensers is minimized while the system short circuit ratios are maintained above a certain level. The presented method is implemented on the simplified western Danish power system for a future scenario.
\end{abstract}

Index Terms-Voltage source converter; fault analysis; short circuit ratio; synchronous condenser.

\section{INTRODUCTION}

Due to the limited overload capability of semiconductors, the replacement of conventional power plants with converterbased renewable energy sources can lead to a significant drop on the system short circuit strength. Short circuit ratio (SCR) is commonly used as an index on the system strength. It is defined as the ratio between the short circuit capacity at the point of common coupling (PCC) and the rated capacity of the device [1]. When the SCR is insufficient, problems such as voltage instability and undesirable dynamic behaviours of converter stations could arise.

In recent years, the application of synchronous condensers is gaining increasing attentions world-widely. A synchronous condenser (SC) is in principle a synchronous machine without the prime mover and has advantages of improving short circuit strength, voltage regulation and system inertia [2], [3]. This helps enhance system stability, facilitates system protection and can improve the operations of converters. However, few studies [4]-[6] have paid attentions to the optimal allocation of SCs. The studies in [4], [5] are developed based on simulations and no optimization procedure is involved to decide the optimal locations and sizes of SCs. Even though [6] can be extended to the optimal SC allocation, a complete power system model is needed in simulation software to perform short circuit analysis, which could be difficult to accomplish for a larger power system. However, if the short circuit analysis is performed analytically using the conventional method [7] to obtain the SCRs, it is insufficient to take the short circuit current contribution from full-scale voltage source converters (VSCs) into account [8].

In this paper, the optimal allocation of SCs is performed through solving an optimization problem, which aims to minimize the cost of installing new SCs while maintaining system SCRs above a certain level. Considering the existence of VSCs, the conventional short circuit analysis method is modified and then used to obtain the SCRs analytically, which does not require a detailed modelling of power systems.

The rest of the paper is organized as follows. The modified short circuit analysis approach is explained and verified through Real Time Digital Simulations (RTDS) in Section II. In Section III, the optimal SC allocation problem is formulated and implemented on the simplified western Danish power system for a future scenario. Finally, Section IV provides the conclusion.

\section{ShORT Circuit ANALYSis}

\section{A. Method}

The conventional short circuit analysis method [7] is developed based on Thevenins theorem. However, a VSC cannot be simply represented by an ideal voltage source behind an impedance for short circuit analysis [9], [10]. Typically, VSCs are current-controlled devices and their short circuit current contributions are restricted due to the limited semiconductor overload capability. Therefore, the conventional short circuit analysis method cannot be directly applied if there are VSCs in the system.

Conventionally, the short circuit model of a synchronous generator ( $\mathrm{SG}$ ) can be represented by a constant-voltage source $\dot{V}_{s}$ in series with its subtransient reactance $x_{d}^{\prime \prime}$ [7]. With Norton's theorem this circuit can be converted into a current source $\dot{I}_{s}$ with a parallel admittance $y_{s}$. The relations 


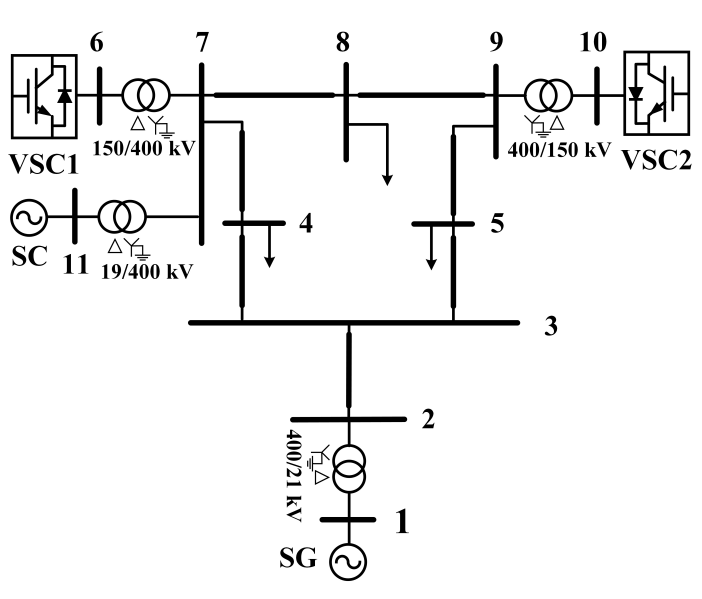

(a)

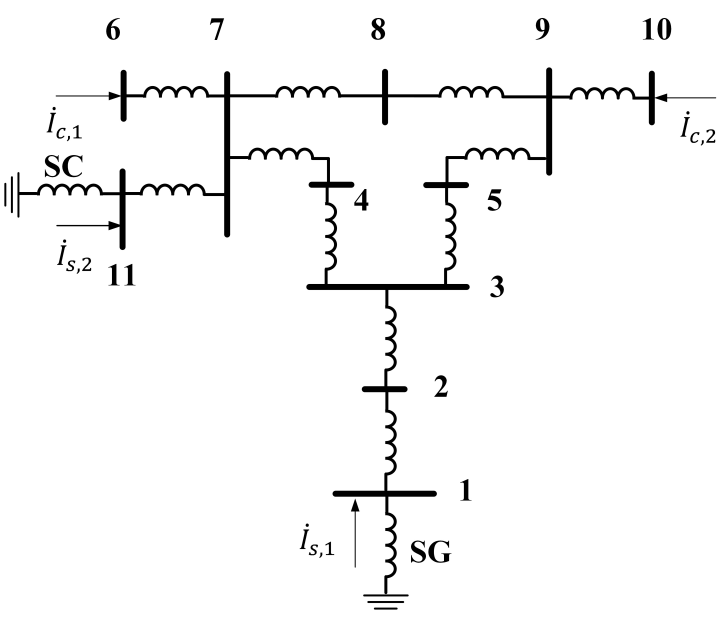

(b)

Fig. 1. (a) Single-line diagram of the test system and (b) its circuit representation.

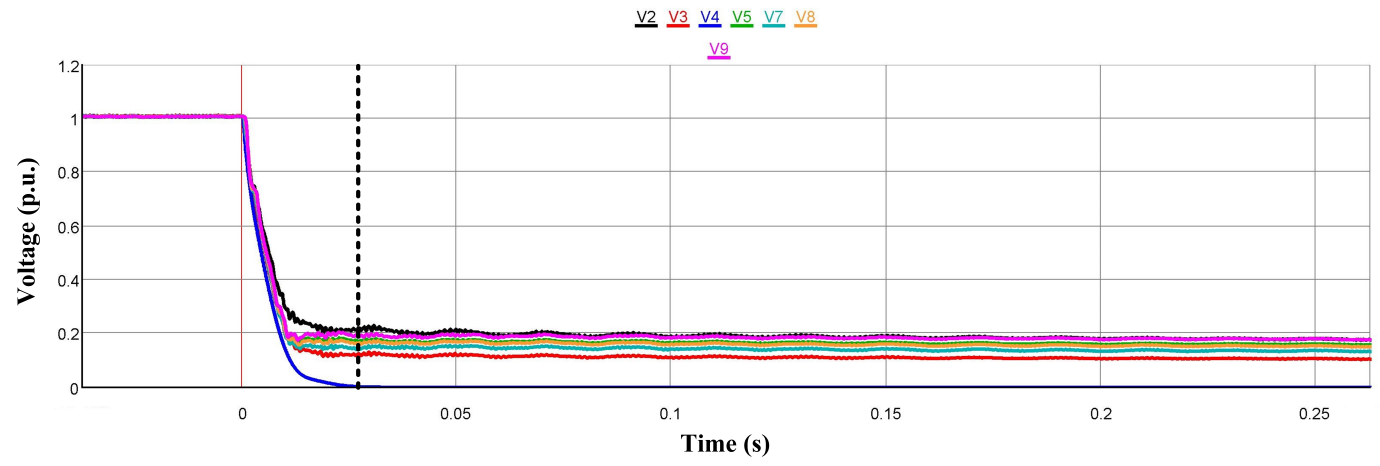

Fig. 2. System voltages subject to a solid three-phase fault on bus 4 .

between the original and its Norton's equivalent circuit can be represented by:

$$
\begin{aligned}
& \dot{I}_{s}=\frac{\dot{V}_{D}}{j x_{d}^{\prime \prime}} \\
& y_{s}=\frac{1}{j x_{d}^{\prime \prime}}
\end{aligned}
$$

Since a SC is in principle a SG without the prime mover, the short circuit model of a SC can also be represented by (1) and (2). Then, with all VSCs ignored but not their interface transformers, the bus admittance matrix $\mathbf{Y}$ of the system can be constructed in a conventional way and the corresponding bus impedance matrix $\mathbf{Z}=\mathbf{Y}^{-1}$ can be derived. If $\dot{I}_{s, m}$ and $\dot{I}_{c, n}$ are referred to the short circuit current contributions from the $m$-th synchronous sources (SG or SC) and the $n$-th VSC respectively, the current injection vector of the system under a balanced fault can be constructed using (3), where a zero means there is no short circuit current injection at the corresponding bus.

$$
\mathbf{I}_{i n j}=\left[\dot{I}_{s, 1}, \ldots, \dot{I}_{s, m}, \dot{I}_{c, 1}, \ldots, \dot{I}_{c, n}, 0, \ldots, 0\right]
$$

With $\mathbf{Z}$ and $\mathbf{I}_{i n j}$ derived, (4) gives the bus voltages of the normal network $\mathbf{V}_{N}$ raised by the short circuit current injection. Then the initial short circuit current at the fault bus $f$ and the voltage drops on all buses $\Delta \mathbf{V}$ caused by the fault can be further expressed by (5) and (6) respectively ( $T$ is the total number of the buses) [11]. Finally, the retained system voltages $\mathbf{V}_{R}$ under the fault can be considered as a superposition of $\mathbf{V}_{N}$ and $\Delta \mathbf{V}$ using (7).

$$
\begin{aligned}
\mathbf{V}_{N} & =\mathbf{Z} \cdot \mathbf{I}_{i n j} \\
\dot{I}_{f} & =\frac{\mathbf{V}_{N}(f, f)}{\mathbf{Z}(f, f)+Z_{f}} \\
\Delta \mathbf{V} & =-[\mathbf{Z}(1, f), \mathbf{Z}(2, f), \mathbf{Z}(3, f), \ldots, \mathbf{Z}(T, f)] \cdot \dot{I}_{f} \\
\mathbf{V}_{R} & =\mathbf{V}_{N}+\Delta \mathbf{V}
\end{aligned}
$$

\section{B. Verifications}

To verify the modified short circuit analysis method, the system shown in Fig. 1(a) is modelled with details in RTDS. In Fig. 1(a), a SG and a SC are connected to bus 1 and bus 11 respectively. Two VSCs (VSC1 and VSC2) are integrated to the system through bus 6 and bus 10 respectively. With all resistances and loads ignored [7], Fig. 1(b) illustrates its Norton's circuit representation. For a grid balanced fault, both 
TABLE I

COMPARISON BETWEEN SIMULATIONS AND CALCULATIONS ON SYSTEM RETAINED VOLTAGES

\begin{tabular}{cccccccc}
\hline \hline Voltage [p.u.] & Bus 2 & Bus 3 & Bus 4 & Bus 5 & Bus 7 & Bus 8 & Bus 9 \\
\hline Simulations & 0.2494 & 0.1433 & 0.0000 & 0.1947 & 0.1601 & 0.1826 & 0.2130 \\
Calculations & 0.2445 & 0.1386 & 0.0000 & 0.1888 & 0.1554 & 0.1768 & 0.2067 \\
\hline Accuracy & $98.04 \%$ & $96.04 \%$ & $100 \%$ & $96.97 \%$ & $97.06 \%$ & $96.82 \%$ & $97.04 \%$ \\
\hline \hline
\end{tabular}

VSCs are controlled to inject 1 p.u. reactive current based on the control structure in [12].

As an example, Fig. 2 shows the RMS voltages of 400 $\mathrm{kV}$ buses subject to a solid balanced fault on bus 4 . The measurements at the indicated time instant are compared to the calculations given by the modified short circuit analysis in Table I. It can be seen that simulations and calculations have similar results, which verifies the effectiveness of the modified short circuit analysis approach. Therefore, (1)-(5) will be deployed in the following section to calculate short circuit ratios for SC allocation.

\section{SyNCHRONOUS CONDENSER ALLOCATION}

\section{A. Formulation and Methodology}

In this paper, the SC allocation is formulated into an optimization problem to decide the optimal locations and sizes of new SCs so that the SCR of each converter PCC is above 3 while maintaining the lowest cost. This can be formulated by:

$$
\text { minimize } \begin{aligned}
F\left(x_{b}, y_{b}\right) & =\sum_{b=1}^{B}\left(C_{F, b}+C_{V, b} \cdot \frac{S_{b}}{y_{b}}\right) \cdot x_{b} \\
\text { subject to } S C R_{j} & \geq 3\left(j \in \pi_{1}\right) \\
\sum_{b=1}^{B} x_{b} & =N\left(b \in \pi_{2}\right) \\
S C R_{j} & =\sqrt{\frac{3}{2}} \cdot \frac{\left|\dot{I}_{f}\right| \cdot V_{n}}{S_{j}}
\end{aligned}
$$

where $\pi_{1}$ and $\pi_{2}$ are the sets of converter PCCs and candidate SC locations respectively; $C_{F, b}$ and $C_{V, b}$ are the fixed and variable costs of installing a new SC at location $b ; S_{b}$ is the rated apparent power of the new installed SC at location $b ; S C R_{j}$ is the short circuit ratio at the $\operatorname{PCC} j ; S_{j}$ is the apparent power rating of converters connected to the PCC $j$.
$V_{N}$ is the nominal system line-line voltage; $N$ is the maximum allowed number of SCs to be installed; $B$ is the total number of candidate locations; $x_{b}$ is a binary decision variable on whether a new SC should be installed at location $b\left(x_{b}=1\right)$ or not $\left(x_{b}=0\right) . y_{b}$ is an integer decision variable to scale the rated $\mathrm{SC}$ apparent power at location $b$. In this paper, SCs with two different rated apparent power (250 Mvar and 125 Mvar) are considered. With $S_{b}$ set to 250 Mvar, $y_{b}=1$ means a $250 \mathrm{Mvar} \mathrm{SC}$ is selected while $y_{b}=2$ represents a 125 Mvar SC is selected. The fixed and variable costs are set respectively equal to 1 million US dollars (M\$) and $3 \mathrm{M}$ \$ per 100 Mvar. This mixed integer non-linear problem is optimized in MATLAB using the genetic algorithm (GA) function of the optimization toolbox [13]. As illustrated in Fig. 3, the GA optimization will provide the decision variables to the modified short circuit analysis approach. With $\mathbf{Y}$ and $\mathbf{I}_{i n j}$ obtained considering the existence of new SCs, the SCR of each converter PCC is calculated and the minimum SCR is returned to the GA optimization.

\section{B. The Western Danish Power System}

Figure 4 shows the single-line diagram of a simplified western Denmark power system for a future scenario, where each $400 \mathrm{kV}$ bus is assigned a three-letter name. The system is developed based on [6] but with new planed lines and the VSC-HVDC link to Holland added to represent a future scenario. Currently, there are already three SCs existing in the system at VHA, TJE and FGD. In order to allocate SCs for a future scenario, the following assumptions are made:

(1) Five conventional SGs (ESVB3, NJVB3, SKVB3, FYVB7 and SSVB3) are assumed to be phased out;

(2) VSC-HVDCs and Type-IV wind farms are assumed to inject 1 p.u. reactive current under grid balanced faults;

(3) The short circuit current contribution from Germany is neglected;

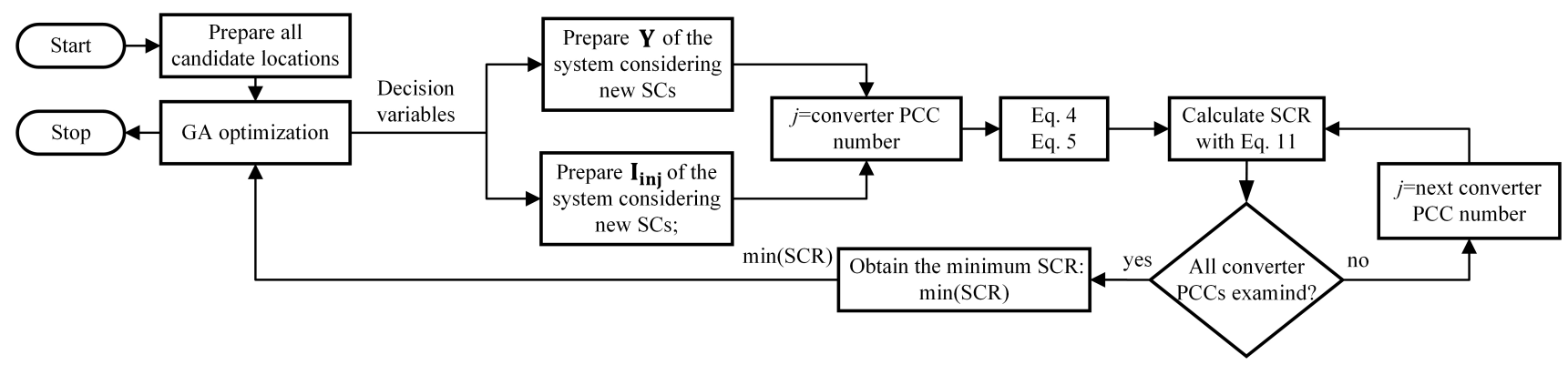

Fig. 3. The flow chart of synchronous condenser allocation. 


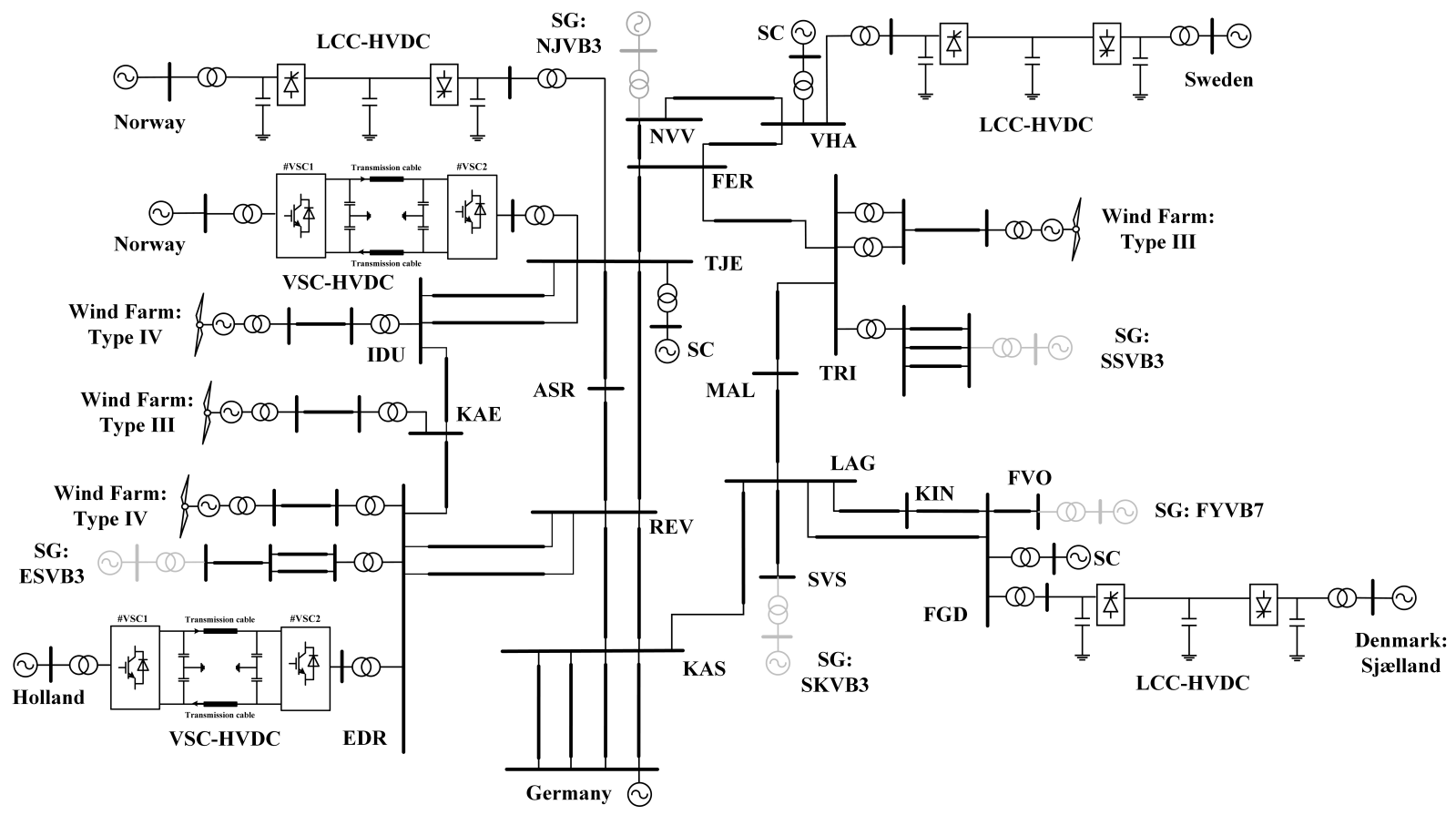

Fig. 4. Single-line diagram of the simplified future western Danish power system.

TABLE II

SYNCHRONOUS CONDENSER ALLOCATION PLAN

\begin{tabular}{c|c|c|c}
\hline \hline Set & Plan & Location and Rating [Mvar] & Cost [M\$] \\
\hline \multirow{3}{*}{1} & 1 & TJE(250), KAE(250), EDR(250), VHA(125) & 30.25 \\
\cline { 2 - 4 } & 2 & TJE(250), KAE(250), EDR(250), TRI(125) & 30.25 \\
\cline { 2 - 4 } & 3 & TJE(250), KAE(250), EDR(250), FGD(125) & 30.25 \\
\hline \multirow{3}{*}{2} & 4 & REV(250), EDR(250), KAE(250) & 25.50 \\
\cline { 2 - 4 } & 5 & $\operatorname{REV(250),~EDR(250),~ASR(250)~}$ & 25.50 \\
\cline { 2 - 4 } & 6 & REV(250), EDR(250), TJE(250) & 25.50 \\
\hline \hline
\end{tabular}

(4) LCC-HVDCs do not contribute any short circuit current under grid balanced faults;

(5) Type-III wind generators are treated as conventional induction motors under grid balanced faults [14], whose Norton's circuit model is represented by:

$$
\begin{aligned}
\dot{I}_{D} & =\frac{n_{D} \dot{V}_{s}}{j\left(X_{s}+X_{r}\right)} \\
y_{D} & =\frac{n_{D}}{j\left(X_{s}+X_{r}\right)}
\end{aligned}
$$

where $X_{s}$ and $X_{r}$ are the stator reactance and rotor reactance of a single Type-III wind generator; $n_{D}$ is a scale factor so that the model is equivalent to the whole wind farm.

\section{Results}

In this paper, two different sets of candidate SC locations are considered. Set 1 only contains converter PCCs at $400 \mathrm{kV}$ level while set 2 contains all $400 \mathrm{kV}$ buses. For each set of candidate locations, the GA optimization is repeated 50 times and Table II summarizes the SC allocation results.

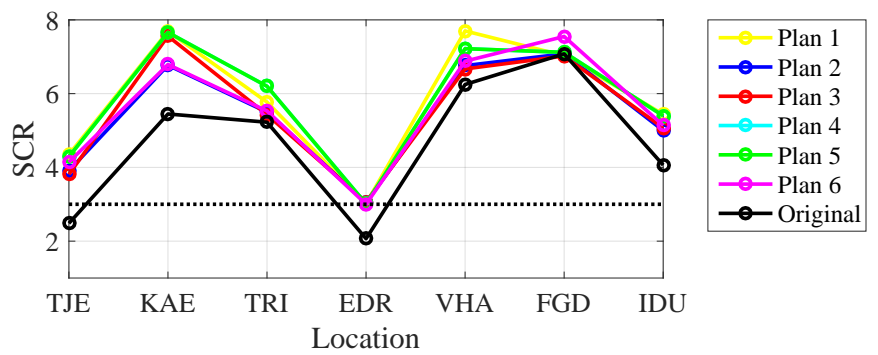

Fig. 5. Comparisons on system SCR under different SC allocation plans.

For set 1 , no feasible solution can be found with $N=1,2$ or 3 . When $N=4$, three different solutions (plan 1, 2 and 3) with the same costs are obtained. On the other hand for set 2, the GA optimization starts to allocate SCs successfully when $N=3$ and three different solutions (plan 4, 5 and 6) with the same costs are obtained, which indicates that less SCs are needed if all $400 \mathrm{kV}$ buses are considered as candidate locations.

This is reasonable because when a SC is located at a converter PCC, it mainly helps increase the SCR locally rather than the other converter PCCs if the SC is relatively far away from the other converters in terms of electrical distance. However, if a SC locates somewhere between two converters properly, the SCRs of both converter PCCs could be improved to some extent.

Figure 5 compares the SCRs of the original system to those of the systems with new installed SCs. It can be seen that EDR and TJE are the weakest points in the original system and their SCRs are below 3. With new installed SCs, the SCRs are all 


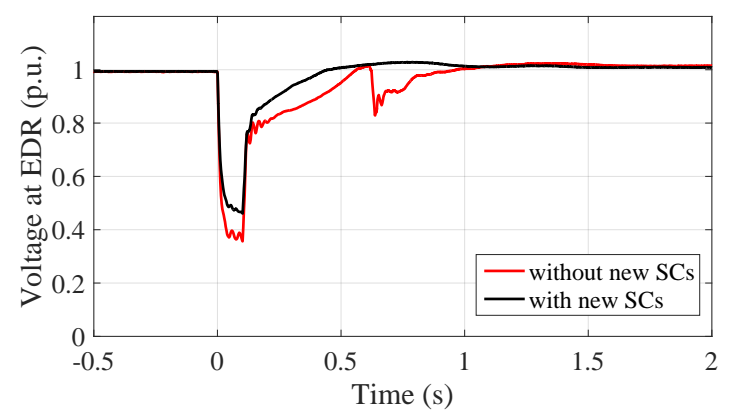

(a)

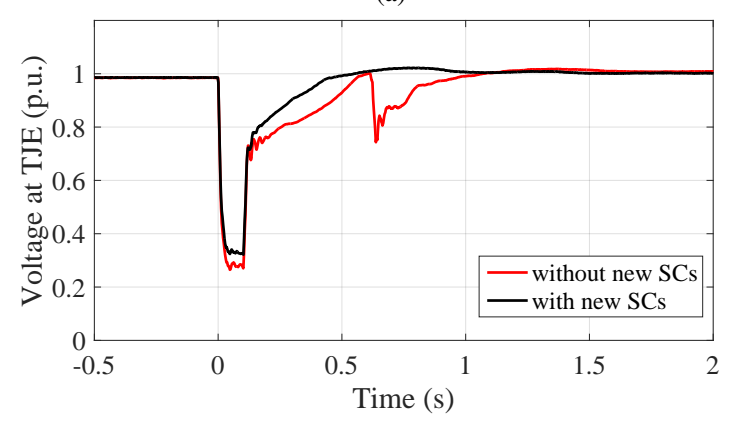

(b)

Fig. 6. Comparisons on voltage response of the original system and the system with plan 4 subject to a balanced fault at REV. (a) EDR. (b) TJE.

above 3 in the new systems. Considering there is a phased-out SG located at EDR near KAE, plan 4 might be the best choice if the refurbishment of existing conventional power plants to SCs is more cost-effective.

In order to illustrate the effect of synchronous condensers, a detailed model of the future western Danish power system in Fig. 4 is simulated in RTDS with all five SGs phased out. In steady state, all five HVDC links and wind farms are in operation. The grid in Germany is represented by a conventional synchronous generator. Under fault conditions, VSC-HVDCs and Type-IV wind farms are controlled to inject 1 p.u. reactive current with respect to their own ratings. For a solid balanced fault initiated at the zero time instant at REV, the red curves in Fig. 6 presents the voltage response of the original system at EDR and TJE. Then with plan 4 adopted, three more SCs are installed at REV, EDR and KAE. With the same fault, the black curves in Fig. 6 plot the voltage response of the new system at EDR and TJE. It can be observed from Fig. 6 that the new system exhibits better fault-ride-through performances than the original system. With the help of the new installed SCs, the new system has higher retained voltages under the fault and has a faster voltage recovery after the fault is cleared.

\section{CONCLUSION}

In this paper, an optimal synchronous condenser allocation method is presented. It is formulated into an optimization problem minimizing the total cost of installing new SCs while maintaining the short circuit ratios at the converter point of common coupling above a certain level. The conventional short circuit analysis method is modified to calculate short circuit ratios taking the short circuit current contributions from full-scale voltage source converters into consideration. The presented method does not require a detailed modelling of power systems and has been implanted on the simplified western Danish power system for a future scenario.

\section{ACKNOWLEDGMENT}

This work is supported by Danish ForskEL project "Synchronous Condensers Application in Low Inertia Systems (SCAPP)", grant no. 12196 administrated by Energinet.dk. The authors would like to thank Energinet.dk for providing the data of the western Danish power system.

\section{REFERENCES}

[1] C. Abbey, B. Khodabakhchian, F. Zhou, S. Dennetiere, J. Mahseredjian, and G. Joos, "Transient modelling and comparison of wind generator topologies," in Proc. International Conference on Power Systems Transients, Montreal, Canada, Jun. 2005, pp. 1-6.

[2] M. Nedd, Q. Hong, K. Bell, C. Booth, and P. Mohapatra, "Application of synchronous compensators in the gb transmission network to address protection challenges from increasing renewable generation," in Proc. Cigre Study Committee B5 Colloquium, Auckland, New Zealand, Sep. 2016, pp. 1-6.

[3] S. Kynev, G. Pilz, and H. Schmitt, "Comparison of modern statcom and synchronous condenser for power transmission systems," in Proc. IEEE Electrical Power and Energy Conference, Ottawa, Canada, Oct. 2016, pp. $1-6$.

[4] N. Masood, R. Yan, T. K. Saha, and S. Barlett, "Post-retirement utilisation of synchronous generators to enhance security performances in a wind dominated power system," IET Generation, Transmission and Distribution, vol. 10, no. 13, pp. 3314-3321, Oct. 2016.

[5] F. Igbinovia, G. Fandi, M. Z, J. Švec, and J. Tlustý, "Optimal location of the synchronous condenser in electric-power system networks," in Proc. International Scientific Conference on Electric Power Engineering, Prague, Czech Republic, May 2016, pp. 1-6.

[6] Z. H. Rather, Z. Chen, P. Thgersen, and P. Lund, "Dynamic reactive power compensation of large-scale wind integrated power system," IEEE Trans. Power Systems, vol. 30, no. 5, pp. 2516-2526, Sep. 2015.

[7] H. Saadat, Power system analysis, 3rd Edition. Arlington, VA, USA: PSA Publishing LLC, 2011.

[8] Q. Wang, N. Zhou, and L. Ye, "Fault analysis for distribution networks with current-controlled three-phase inverter-interfaced distributed generators," IEEE Trans. Power Systems, vol. 30, no. 3, pp. 1532-1542, Feb. 2015.

[9] C. A. Plet and T. C. Green, "Fault response of inverter interfaced distributed generators in grid-connected applications," Electric Power System Research, vol. 106, pp. 21-28, Feb. 2014.

[10] D. V. Tu, S. Chaitusaney, and A. Yokoyama, "Maximum-allowable distributed generation considering fault ride-through requirement and reach reduction of utility relay," IEEE Trans. Power Del., vol. 29, no. 2, pp. 534-541, Feb. 2014.

[11] E. Muljadi, C. Butterfield, J. Conto, and K. Donohoo, "Ride-though capability predictions for wind power plants in the ercpot netwook," in Proc. IEEE Power Engineering Society General Meeting, San Francisco, CA, USA, Jun. 2005, pp. 1-8.

[12] M. M. Alam, L. H, J. Liang, and A. D. S. Carvalho, "Effects of vsc based hvdc system on distance protection of transmission lines," Electrical Power and Energy Systems, vol. 92, pp. 245-246, Nov. 2017.

[13] (2017, Dec.) The mathwoks online help guides. [Online]. Available: https://se.mathworks.com/help/gads/ga.html

[14] "Wind power plant short-circuit modeling guide," Sandia National Laboratories, Albuquerque, NM and Livermore, CA, Tech. Rep. SAND20126664, Aug. 2012. 